\title{
Agroindustrial Exploitation of the Mucilage Obtained from the Nopal Cactus Opuntia spp. Cultivated in Hydroponics
}

\author{
Brenda Luna-Sosa, Guillermo C.G. Martínez-Ávila, Dulce C. González-Sandoval, Humberto Rodríguez-Fuentes, \\ Ernesto Sanchez-Alejo and Romeo Rojas* \\ Universidad Autónoma de Nuevo León, School of Agronomy, General Escobedo 66050, Nuevo León, México.
}

*Corresponding author: Romeo Rojas, Universidad Autónoma de Nuevo León, School of Agronomy, General Escobedo 66050, Nuevo León, México.

Submission: January 25, 2019; Published: February 04, 2019

\begin{abstract}
Nopal mucilage is a hetero-polysaccharide hydrocolloid with an extensive range of properties that can be used for the food, cosmetic, pharmaceutical and other industries. However, to promote the efficient cultivation can be used the hydroponic system using regional varieties like Copena F1, Villanueva and Jalpa. These varieties are perfectly adapted to a hydroponic system with which you can obtain high quality mucilage and in large quantity. The results shown high yields (16.47g $13.76 \mathrm{~g}$ and $8.74 \mathrm{~g} 100 \mathrm{~g}-1$ of "fresh matter") for Copena F1, Villanueva and Jalpa respectively. This demonstrate that the hydroponic system and these varieties are a potential source of mucilage that can be used in several industrial sectors.
\end{abstract}

Keywords: Mucilage; Hydroponic; Nopal cactus

\section{Introduction}

The development of new biodegradable materials obtained from by-products and/or agricultural waste is a new global trend that promotes environmental protection through green chemistry to produce organic products [1]. Therefore, the nopal is considered a cactus present in the roads of rural and semi-urban Mexico, it is an entire Mexican cultural symbol with multiple medicinal, agricultural and environmental uses, useful for its investigation. In recent years, the hydroponic cultivation of this cactus has allowed us to obtain greater productivity due to the optimal availability of nutrients with a reduction in water consumption [2]. Research based on the production of nopal in hydroponic systems is very scarce and novel. The yields of Opuntia spp. reported in Sonora, Morelos, Mexico City, Baja California, Jalisco, Oaxaca and Nuevo Leon range from 60 to $80 \mathrm{t} \mathrm{ha}^{-1}$ per year [3]. The cactus hydroponic cladodes contain a thick white cuticle on the inside with cavities of scattered cellulose layers that make up the collenchyma and chlorenchyma, which make up the parenchyma, which is the one that produces mucilage. Among these tissues are cells with oxalate crystals (drusen) and soluble and insoluble fibers in an aqueous medium. It is expected that, the greater the area and surface thickness of each cladode, the larger the mucilage content will be the composition of this polymer consists of L-arabinose (47\%), D-xylose (23\%), D-galactose (18\%), L-rhamnose (7\%) and D-galacturonic acid (5\%). It is also characterized by having minerals such as calcium (4.15\%), potassium (3.76\%), sodium (0.36\%), magnesium (0.81\%), phosphorus $(0.11 \%)$, zinc (3.64\%), iron (21.07\%), copper $(1.56 \%)$; protein $(5.77 \%)$, fat $(4.27 \%)$, reducing sugars $(6.22 \%)$ and fibers (56.68\%) [4]. Mucilage are a functional source that have applications in the food, pharmaceutical, construction and cosmetic industries [5-8].

\section{Hydroponic mucilage's obtained from different Opuntia spp. cultivars}

The mucilaginous compounds are not extracted spontaneously from vegetables; grinding and solvents must be used for extraction in most of the cases. In general, when in contact with water, mucilage's swell forming highly viscous solutions and non-adherent gels that are able to absorb their weight in water. The cactaceae correspond to the classification of neutral mucilage's because their chemical structure presents heterogeneous polymers of the mannose that incorporate in their structure a variable percentage of other proteins. The cultivar Copena $\mathrm{F}_{1}\left(\mathrm{CF}_{1}\right)$ and Opuntia undulata are called "triple purpose", this term refers to the production of vegetable nopal for human consumption, production of prickly pear and forage. The mucilage's obtained from the triple purpose cultivars have the main characteristic of having a weakly acidic $\mathrm{pH}$ (5.19-5.39), however, CF1 contains a greater amount of mucilage (16.47g $100 \mathrm{~g}-1$ of prickly pear). On the other hand, Villanueva (Vi) and Jalpa (Jap) are considered only for one application, the buds of the mother clade are used as a vegetable. The $\mathrm{pH}$ for Vi ranges from 5.58 and Jap from 5.47, which probably these values may be affected by the accumulation of malic acid in plants. The yield of the polysaccharide for Villanueva turns out to be around 13.76 and in Jalpa it is $8.74 \mathrm{~g}$ and $100 \mathrm{~g}-1$ of fresh matter. The differences are related by the method and conditions of extraction of the mucilage, as well as the surface area and humidity of the cladodes from which these polysaccharides were extracted. 
Currently, there are several extraction methods for obtaining mucilage extracted from nopal cactus and reported by different authors for various agro-industrial uses [9-11]. Therefore, in this process the phenomenon of density, viscosity and degree of methoxylation must be considered, since the addition of some solvent can generate an inhibition of undesired enzymatic lysis. In general, the procedure consists of
a) Disinfection of the vegetative material
b) Dehydration of cladodes
c) Homogenization of the suspension
d) Condensation of the suspension
e) Elimination of traces
f) Recovery of mucilage
g) Drying and pulverized

The incorporation of the solvent is related to the fresh weight of the vegetative matter and the degree of purity. Normally the proportions managed for the addition of alcohol are 1:1 and 2:1 $(\mathrm{v} / \mathrm{v})$. The characteristic color of the mucilage is white, however, during the saturation by alcohol, the chlorophyll pigments are extracted simultaneously due to the chemical affinity they present to the hydrocolloids. The $\mathrm{pH}$ is released acidically, leaving the soluble solids concentrate as sucrose.

Several studies have evaluated the use of mucilage in the purification and filtration of sewage water contaminated by heavy metals, also as an adhesive in the textile industry, enhancer in the infiltration of water in soils due to its physical properties (viscosity, elasticity and texture) for the optimal germination of seeds. These are also used in construction, since they have shown to improve the properties of concrete both in its fresh and hardened state (CIIDIR 2018). Another application of the mucilage in the food area includes the production of films and/or coatings to extend the shelf life of perishable products before, during and after harvest.

\section{Conclusion}

The industrial potential of the hydroponic mucilage's derived from cactus plants of different cultivars (Copena F1, Villanueva, and Jalpa) of biological basis and suitable for human consumption turn out to be an alternative study in the physicochemical properties of fibers that constitute them.

\section{Acknowledgment}

This research was funded by FONDO CONACYT-CONAFOR, grant number 2018-1-B-S-65769. C. Luna Sosa and C. GonzálezSandoval thanks the Mexican Council for Science and Technology (CONACYT) for this post-graduate scholarship.

\section{References}

1. Gheribi R, Puchot L, Verge P, Grayaa NJ, Mezni M, et al. (2018) Development of plasticized edible films from opuntia ficus-indica mucilage: A comparative study of various polyol plasticizers. Carbohydrate Polymers 190: 204-211.

2. Jung DH, Kim HJ, Cho WJ, Park SH, Yang SH (2019) Validation testing of an ion-specific sensing and control system for precision hydroponic macronutrient management. Computers and Electronics in Agriculture 156: 660-668.

3. https://www.gob.mx/cms/uploads/attachment/file/222630/Boletin de_exportaciones_nopalitos_2017_05.pdf

4. Padilla MC, García MER, Cortez EG, Bravo MCV, Molina JIR, et al. (2016) Physicochemical and rheological characterization of opuntia ficus mucilage at three different maturity stages of cladode. European Polymer Journal 78: 226-234.

5. Martínez FML, Barrita PFC, Rivera LL, Torres LM (2014) Study of nopal mucilage and marine brown algae extract as viscosity-enhancing admixtures for cement-based materials. Construction and Building Materials 53: 190-202.

6. Torres LM, Cruz EEG, Calderas F, Laredo RFG, Olivares GS, et al. (2013) Microencapsulation by spray drying of gallic acid with nopal mucilage (Opuntia ficus indica). LWT - Food Science and Technology 50(2): 642650.

7. Gutiérrez TM, Damián MTM, Prieg AFB, Vázquez CG, Pérez JER, et al. (2017) Evaluation of some physical and chemical characteristics of fruits of xocotuna, tuna and xoconostle in postharvest. Revista Mexicana de Ciencias Agrícolas 8(1): 189-197.

8. Zaragoza MLZ, Cortez EG, Real AD, Reza RMG, Pérez MJG, et al. (2014) Fresh-cut red delicious apples coating using tocopherol/mucilage nano-emulsion: Effect of coating on polyphenol oxidase and pectin methylesterase activities. Food Research International 62: 974-983.

9. Mendoza B, Gómez E, Hernández E, Rodríguez A, Chavarría N (2014) Elaboración y caracterización de películas biodegradables a partir de mucilago de nopal-caseinato de sodio y mucilago de nopal-pectina. Ciencias Agropecuarias 1(1): 129-136.

10. https://www.gob.mx/siap

11. Garza MZT, García S, Heredia N, Guzmán MGA, Niño KA (2017) Layerby-layer edible coatings based on mucilages, pullulan and chitosan and its effect on quality and preservation of fresh-cut pineapple (Ananas comosus). Postharvest Biology and Technology 128: 63-75.

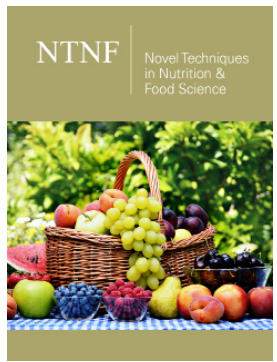

Novel Techniques in Nutrition and Food Science

\section{Benefits of Publishing with us}

- High-level peer review and editorial services

- Freely accessible online immediately upon publication

- Authors retain the copyright to their work

- Licensing it under a Creative Commons license

- Visibility through different online platforms 